\title{
ROTATION ASSESSMENT IN ADOLESCENT IDIOPATHIC SCOLIOSIS WITH ROD DEROTATION
}

\author{
AVALIAÇÃO DA ROTAÇÃO NA ESCOLIOSE IDIOPÁTICA DO \\ ADOLESCENTE COM DERROTAÇÃO DA HASTE
}

\author{
Fernando Flores de Araujo ${ }^{1}$, Raphael Martus Marcon ${ }^{1}$, Alexandre Fogaça Cristante $^{1}$, Tarcisio Eloy Pessoa de Barros Fillo ${ }^{1}$, Olavo Biraghi LetalF ${ }^{1}$ \\ 1. Universidade de São Paulo, Faculdade de Medicina, Hospital das Clínicas (IOT-HCFMUSP), Instituto de Ortopedia e Traumatologia, Spine Surgery Division, São Paulo, SP, Brazil.
}

\section{ABSTRACT}

Objective: Adolescent idiopathic scoliosis (AIS) is characterized by rotational and lateral deformity of the spine. The measurement of vertebral rotation is important for prognosis and treatment. Our objective was to evaluate whether the Nash-Moe method can be used to measure axial deformity correction with surgical treatment using the rod derotation maneuver at both the apex and extremities of the deformity in patients with AIS. Methods: Rotation was assessed using the Nash and Moe criteria, on preoperative and postoperative radiographs. We also evaluated the severity on the coronal plane using the Cobb method, ratio of correction achieved, screw density, and number of vertebrae involved in the instrumentation. Results: The Cobb method correction average was $54.8 \%$. When we disregarded vertebrae that presented preoperative Nash-Moe grade 0, the average measurable correction was $54.5 \%$ in the first non-instrumented vertebra above, $69.2 \%$ in the first instrumented vertebra, $32.2 \%$ in the apical vertebra, $36.8 \%$ in the last instrumented vertebra, and $30 \%$ in the first non-instrumented vertebra below. In our study, $32.14 \%$ of the patients presented a measurable correction in the apical vertebra. Conclusion: On the axial plane, correction can be satisfactorily evaluated using the Nash-Moe method. Level of Evidence VI. Case Series.

Keywords: Scoliosis. Deformity. Spine.

\section{RESUMO}

Objetivo: A escoliose idiopática do adolescente é caracterizada por deformidade rotacional e lateral da coluna vertebral. A medição da rotação vertebral é importante para o prognóstico e tratamento. Nosso objetivo foi avaliar se o método de Nash-Moe pode ser usado para medir a correção da deformidade axial com o tratamento cirúrgico usando a manobra de derotação em ambos os ápices e extremidades da deformidade em pacientes com EIA. Métodos: A rotação foi avaliada usando os critérios de Nash e Moe em radiografias pré e pós-operatórias. Também avaliamos a severidade no plano coronal pelo método de Cobb, a razão de correção alcançada, a densidade do parafuso e o número de vértebras envolvidas na instrumentação. Resultados: A correção do método de Cobb foi de $54,8 \%$. Quando desconsideramos vértebras que apresentavam grau Ono pré-operatório de Nash-Moe, encontramos, em média, 54,5\% de correção mensurável na primeira vértebra não instrumentada acima, $69,2 \%$ na primeira vértebra instrumentada, 32,2\% na vértebra apical, $36,8 \%$ na última vértebra instrumentada e $30 \%$ na primeira vértebra não instrumentada abaixo. Em nosso estudo, 32,14\% dos pacientes apresentaram uma correção mensurável na vértebra apical. Conclusão: No plano axial, a correção pode ser avaliada satisfatoriamente pelo método de Nash-Moe. Nível de Evidência VI. Série de casos.

Descritores: Escoliose. Deformidade. Coluna.

Citation: Araujo FF, Marcon RM, Cristante AF, de Barros-Filho TEP, Letaif OB. Rotation assessment in adolescent idiopathic scoliosis with rod derotation. Acta Ortop Bras. [online]. 2019;27(1):42-5. Available from URL: http://www.scielo.br/aob.

\section{INTRODUCTION}

Adolescent idiopathic scoliosis is characterized by rotational and lateral deformity of the spine and no defined pathological cause or process. ${ }^{1-3}$ The Cobb angle measurement has been used to quantify the severity of AIS; however, this method is limited to sagittal and coronal plane evaluation. The measurement of vertebral rotation is important for defining the prognosis and treatment. ${ }^{4}$ To measure the vertebral rotation, the method of Nash and $\mathrm{Moe}^{5}$ is commonly used. One of the first forms developed for instrumentation in the surgical treatment of scoliosis was the Harrington system ${ }^{6}$. However, this technique can cause loss of the sagittal curvature. ${ }^{7}$ Subsequently,
Cotrel et al. ${ }^{8}$ developed a system of segmental instrumentation with better correction of the scoliotic curve on both the coronal and sagittal planes. The disadvantages are the increased surgical time and the risk of spinal cord injury. ${ }^{9}$ Currently, fixation of the spine using pedicular screws is emphasized because they offers safety, rigidity in assembly and better three-dimensional correction. This procedure is considered a reliable and safe method of instrumentation and preserves mobility with the smallest number of segments submitted to arthrodesis. ${ }^{10-12}$

In 1988, Cotrel et al. ${ }^{8}$ described a maneuver that consists of derotating a pre-shaped rod similar to the physiological sagittal curvature,

All authors declare no potential conflict of interest related to this article.

Study was conducted at the Orthopedics and Traumatology Institute of HC/FMUSP-São Paulo, Brazil.

Correspondence: Fernando Flores de Araujo, Rua Dr. Ovídio Pires de Campos, 333 Cerqueira César, São Paulo, SP 05403-010. fernando_araujo87@hotmail.com 
resulting in conversion of the coronal curve into sagittal curvature without additional compression or distraction..$^{8,13}$ Suk $^{12}$ and Lee et al. ${ }^{14}$ described the application of Direct Vertebral Rotation (DVR) to the apical vertebra for correction of the vertebral rotation. This maneuver cannot be performed without pedicular screws and specialized instruments. We use the derotation maneuver to correct scoliotic curves, ${ }^{8}$ and do not routinely perform DVR $^{12}$ because literature shows that rod derotation affects the deformity on the axial plane, because of the translation of the rotated vertebra. ${ }^{11,15-18}$ The objective of the study was to evaluate whether the Nash-Moe method can be used to measure axial deformity correction with surgical treatment using the rod derotation at both the apex and extremities of the deformity in patients with AIS.

\section{MATERIALS AND METHODS}

The study was a transversal, retrospective case series, and the sample was selected by convenience by analyzing medical records with imaging exams of patients diagnosed with AIS submitted to surgical treatment at our service from June 2013 to August 2014 with a minimum follow-up of 2 years. The study was approved by the institutional research ethics committee: Comitê de Ética e Pesquisa do Instituto de Ortopedia e Traumatologia do Hospital das Clínicas de São Paulo - CEP/IOT-HCFMUSP - number 1482.353; CAAE: 5472.5216.8.0000.0068. All the participants signed the Free and Informed Consent Form.

The parameters were evaluated based on panoramic orthostatic radiographs as recommended by the Scoliosis Research Society (SRS).$^{19}$ Rotation was assessed using the Nash and Moe criteria ${ }^{5}$ on pre- and postoperative radiographs.

The following parameters were evaluated with the Nash and Moe method: ${ }^{5}$ the last non-instrumented vertebra above the first vertebra of the instrumentation, the first instrumented vertebra, the apical vertebra, the last instrumented vertebra, and the first non-instrumented vertebra below the last vertebra of the instrumentation.

We also evaluated the severity of the scoliotic curve using the Cobb method both pre- and postoperatively, and the ratio of correction achieved. Another parameter included in the evaluation was the screw density across the curve and at the apex of the main curve (considering the 3 vertebrae at the apex of the main curve), in addition to the number of vertebrae involved in the instrumentation and whether there was a correlation between the screw density across the curve and at the apex with greater angular correction. The inclusion criteria were: patients with AIS diagnoses followed at the outpatient clinic of the Spine Surgery Division; between 10 and 17 years old when submitted to surgical treatment with pedicle screw instrumentation; surgical correction performed using the rod derotation maneuver ${ }^{8}$; and image examinations of good technical quality that included full spine radiographs (front + lateral) before and after surgery. The following exclusion criteria were used: patients with other diagnoses; surgical treatment with other correction techniques; incomplete medical records or imaging tests; patients without 2 years of follow-up. The results of the measurement of vertebral rotation between the radiographs by the Nash-Moe method were compared between the pre- and postoperative periods. To determine whether statistical relationships existed between the data from the pre- and postoperative periods, we used Pearson's chi-square test.

\section{RESULTS}

We included 28 patients who met the inclusion criteria, with a predominance of female patients (96.4\%) over male patients (3.6\%); the mean age at the time of surgical treatment was 14.5 years old. In the preoperative period, the mean value was $78.3^{\circ}$ whereas in the postoperative period, the mean value was $36.3^{\circ}$, corresponding to a mean correction of $54.8 \%$. On average, the implant density was $74.6 \%$ with a peak density of $62 \%$, and the mean number of vertebrae involved in the instrumentation was 11.9 (Table 1). No correlation existed between the implant density of the scoliotic curve and the degree of correction or between the implant density at the apex of the main curve and the degree of correction.

Regarding the preoperative Nash-Moe grades, grade 0 was found for the non-instrumented vertebra above in $60.7 \%$, grade 1 in $32.1 \%$ and grade 2 in $7.1 \%$. The first instrumented vertebra presented grade 0 in $53.6 \%$, grade 1 in $39.3 \%$ and grade 2 in $7.2 \%$. The apical vertebra presented grade 1 in $14.3 \%$, grade 2 in $32.1 \%$, grade 3 in $42.9 \%$ and grade 4 in $10.7 \%$; no cases with grade 0 were found. The last instrumented vertebra presented grade 0 in $32.1 \%$, grade 1 in $42.9 \%$ and grade 2 in 25\%, whereas the first non-instrumented vertebra below had grade 0 in $64.3 \%$, grade 1 in $32.1 \%$ and grade 2 in $3.6 \%$ (Table 2).

Regarding the postoperative Nash-Moe grades, the non-instrumented vertebra above presented degree 0 in $75 \%$ and degree 1 in $25 \%$. The first instrumented vertebra presented grade 0 in $67.9 \%$ and grade 1 in $32.1 \%$. The apical vertebra showed grade 0 in $3.6 \%$, grade 1 in 25\%, grade 2 in $32.1 \%$, grade 3 in $32.1 \%$ and grade 4 in $7.1 \%$. The last instrumented vertebra presented grade 0 in $50 \%$, grade 1 in $32.1 \%$ and grade 2 in $17.9 \%$, whereas the noninstrumented vertebra below presented grade 0 in $75 \%$, grade 1 in $21.4 \%$ and grade 2 in $3.6 \%$ (Table 3 ).

Comparing the Nash-Moe value between the preoperative and postoperative periods relative to the non-instrumented vertebra, when the preoperative grade was 1,55.6\% maintained grade 1 , and $44.4 \%$ changed to grade 0 . In contrast, when the preoperative grade was $2,100 \%$ changed to grade $1(p<0.05)$.

Table 1. Characteristics of 27 Female Patients and 1 Male Patient.

\begin{tabular}{c|c|c|c}
\hline & average & Variation & IC 95\% \\
\hline Age & 14.5 years & $11-17$ & $13.7-15.3$ \\
\hline Preoperative Cobb & $78.3^{\circ}$ & $46-121$ & $71.9-84.7$ \\
\hline Postoperative Cobb & $36.3^{\circ}$ & $15-73$ & $30.1-42.4$ \\
\hline Curve correction & $54.8 \%$ & $29-71$ & $49.7-59.9$ \\
\hline Screw Density & $74.6 \%$ & $58-100$ & $70.5-78.6$ \\
\hline Screw density at apex & $62 \%$ & $16-100$ & $54.4-69.5$ \\
\hline $\begin{array}{c}\text { Number of vertebrae } \\
\text { involved in arthrodesis }\end{array}$ & 11.9 & $7-15$ & $11.1-12.7$ \\
\hline
\end{tabular}

Table 2. Preoperative Nash-Moe Frequency.

\begin{tabular}{c|c|c|c|c|c}
\hline & Nash-Moe & & & & \\
\hline $\begin{array}{c}\text { Vertebra not } \\
\text { instrumented above }\end{array}$ & $60.7 \%$ & $32.1 \%$ & $7.2 \%$ & 0 & 0 \\
\hline $\begin{array}{c}\text { First instrumented } \\
\text { vertebra }\end{array}$ & $53.6 \%$ & $39.3 \%$ & $7.1 \%$ & 0 & 0 \\
\hline Apical vertebra & 0 & $14.3 \%$ & $32.1 \%$ & $42.9 \%$ & $10.7 \%$ \\
\hline $\begin{array}{c}\text { Last instrumented } \\
\text { vertebra }\end{array}$ & $32.1 \%$ & $42.9 \%$ & $25 \%$ & 0 & 0 \\
\hline $\begin{array}{c}\text { Vertebra not } \\
\text { instrumented below }\end{array}$ & $64.3 \%$ & $32.1 \%$ & $3.6 \%$ & 0 & 0 \\
\hline \multicolumn{4}{c|}{}
\end{tabular}

Table 3. Postoperative Nash-Moe Frequency.

\begin{tabular}{c|c|c|c|c|c}
\hline & Nash-Moe & & & & \\
\hline & $\mathbf{0}$ & $\mathbf{1}$ & $\mathbf{2}$ & $\mathbf{3}$ & $\mathbf{4}$ \\
\hline $\begin{array}{c}\text { Vertebra not } \\
\text { instrumented above }\end{array}$ & $75 \%$ & $25 \%$ & 0 & 0 & 0 \\
\hline First instrumented vertebra & $67.9 \%$ & $32.1 \%$ & 0 & 0 & 0 \\
\hline Apical vertebra & $3.6 \%$ & $25 \%$ & $32.1 \%$ & $32.1 \%$ & $7.1 \%$ \\
\hline Last instrumented vertebra & $50 \%$ & $32.1 \%$ & $17.9 \%$ & 0 & 0 \\
\hline $\begin{array}{c}\text { Vertebra not } \\
\text { instrumented below }\end{array}$ & $75 \%$ & $21.4 \%$ & $3.6 \%$ & 0 & 0 \\
\hline
\end{tabular}


Regarding the first instrumented vertebra, when the preoperative grade was $1,63.6 \%$ maintained the same degree, and $36.4 \%$ changed to grade 0 . In contrast, when the preoperative grade was $2,100 \%$ changed to grade $1(p<0.05)$

Regarding the apical vertebra, when the preoperative degree was 1 , $75 \%$ maintained the same degree, and $25 \%$ regressed to grade 0. In contrast, when the preoperative grade was 2, 66.7\% maintained the same grade, and $33.3 \%$ regressed to grade 1 ; none regressed to grade 0 . When the preoperative grade was 3, 66.7\% maintained the same grade, $25 \%$ regressed to grade 2 , and $8.3 \%$ regressed to grade 1 . When the preoperative grade was $4,66.7 \%$ maintained the same grade, and $33.3 \%$ regressed to grade $3(p<0.05)$ (Table 4$)$. Regarding the last instrumented vertebra, when the preoperative grade was 1, 58.3\% maintained the same degree, and $44.7 \%$ regressed to grade 0 . In contrast, when the initial degree was 2 , $71.4 \%$ maintained the same grade, $28.6 \%$ regressed to grade 1 , and none were reduced to grade 0 .

Considering the non-instrumented vertebra below, when the preoperative grade was 1,66.7\% maintained the same degree, and $33.3 \%$ regressed to grade 0 . In contrast, when the preoperative grade was $2,100 \%$ maintained the same grade ( $p<0.05)$. In all of the vertebrae evaluated, when the preoperative grade was 0 , no change was observed in the postoperative period

On average, $21.4 \%$ of the patients had a measurable correction in the above non-instrumented vertebra, $21.4 \%$ of the patients in the first instrumented vertebra, $32.2 \%$ in the apical vertebra, $25 \%$ in the last instrumented vertebra, and $10.7 \%$ in the first non-instrumented below. However, vertebrae with neutral rotation (i.e., Nash-Moe grade 0) were not expected to undergo postoperative correction (Table 5). When we disregarded the vertebrae that presented preoperative NashMoe grade 0 , we found, on average, $54.5 \%$ exhibited a measurable correction in the above non-instrumented vertebra, $69.2 \%$ in the first instrumented vertebra, $32.2 \%$ in the apical vertebra, $36.8 \%$ in the last instrumented vertebra and $30 \%$ in the first non-instrumented vertebra below. In all of the vertebrae evaluated, when the preoperative grade

\begin{tabular}{|c|c|c|c|c|c|c|}
\hline & Post & & & & & \\
\hline Pre & 0 & 1 & 2 & 3 & 4 & \\
\hline 0 & 0 & 0 & 0 & 0 & 0 & \\
\hline 1 & $1(25 \%)$ & $3(75 \%)$ & 0 & 0 & 0 & $p<0.05$ \\
\hline 2 & 0 & $3(33.3 \%)$ & $6(66.7 \%)$ & 0 & 0 & $p<0.05$ \\
\hline 3 & 0 & $1(8.3 \%)$ & $3(25 \%)$ & $8(66.7)$ & 0 & $p<0.05$ \\
\hline 4 & 0 & 0 & 0 & $1(33.3 \%)$ & $2(66.7 \%)$ & $p<0.05$ \\
\hline Total & 1 & 7 & 9 & 9 & 2 & 28 \\
\hline
\end{tabular}

Table 5. Number of Vertebrae with a Measurable Correction.

\begin{tabular}{c|c|c|c|c|c|c}
\hline & $\begin{array}{c}\text { Relative } \\
\text { Correction by } \\
\text { Nash-Moe } \\
\text { Grade }\end{array}$ & & & & & $\begin{array}{c}\text { Total } \\
\text { Correction } \\
\text { per Vertebra } \\
\text { Measured }\end{array}$ \\
\hline $\begin{array}{c}\text { Preoperative } \\
\text { Nash-Moe grade }\end{array}$ & 0 & 1 & 2 & 3 & 4 & \\
\hline $\begin{array}{c}\text { Vertebra not } \\
\text { instrumented above }\end{array}$ & 0 & $44.4 \%$ & $100 \%$ & 0 & 0 & $21.4 \%$ \\
\hline $\begin{array}{c}\text { First instrumented } \\
\text { vertebra }\end{array}$ & 0 & $36.4 \%$ & $100 \%$ & 0 & 0 & $21.4 \%$ \\
\hline Apical vertebra & 0 & 0 & $33.3 \%$ & $33.3 \%$ & $33.3 \%$ & $32.2 \%$ \\
\hline $\begin{array}{c}\text { Last instrumented } \\
\text { vertebra }\end{array}$ & 0 & $41.7 \%$ & $28.6 \%$ & 0 & 0 & $25 \%$ \\
\hline $\begin{array}{c}\text { Vertebra not } \\
\text { instrumented below }\end{array}$ & 0 & $33.3 \%$ & 0 & 0 & 0 & $10.7 \%$ \\
\hline
\end{tabular}

was 0 , no change was observed in the postoperative period (Table 6). This absence of unexpected response to neutral rotation also contributed to the validation of the method. The correlations were statistically significant, demonstrating that the axial correction promoted by the Nash-Moe method of indirect derotation can be measured.

\begin{tabular}{|c|c|c|c|c|c|}
\hline & $\begin{array}{c}\text { Relative } \\
\text { Correction by } \\
\text { Nash-Moe } \\
\text { Grade }\end{array}$ & & & & $\begin{array}{c}\text { Total } \\
\text { Correction } \\
\text { per Vertebra } \\
\text { Measured }\end{array}$ \\
\hline $\begin{array}{c}\text { Preoperative } \\
\text { Nash-Moe grade }\end{array}$ & 1 & 2 & 3 & 4 & \\
\hline $\begin{array}{c}\text { Vertebra not } \\
\text { instrumented above }\end{array}$ & $44.4 \%$ & $100 \%$ & 0 & 0 & $54.5 \%$ \\
\hline First instrumented vertebra & $36.4 \%$ & $100 \%$ & 0 & 0 & $69.2 \%$ \\
\hline Apical vertebra & 0 & $33.3 \%$ & $33.3 \%$ & $33.3 \%$ & $32.2 \%$ \\
\hline Last instrumented vertebra & $41.7 \%$ & $28.6 \%$ & 0 & 0 & $36.8 \%$ \\
\hline $\begin{array}{c}\text { Vertebra not } \\
\text { instrumented below }\end{array}$ & $33.3 \%$ & 0 & 0 & 0 & $30 \%$ \\
\hline
\end{tabular}

\section{DISCUSSION}

Kadoury et al. ${ }^{15}$ evaluated the degree of scoliosis correction on the three planes of the deformity with a three-dimensional reconstruction model using paired $\mathrm{X}$-rays in AP and profile. Harrington-Luque instrumentation, ${ }^{6,7} \mathrm{CD}$ indirect derotation ${ }^{8}$ and the direct vertebral derotation of Suk were compared, and the results indicated that spinal correction on the coronal plane exhibited the same tendency for the three types of instrumentation. Regarding spinal correction on the sagittal plane, both the CD indirect derotation ${ }^{8}$ and third-generation pedicle screws restore the physiological values of thoracic kyphosis and lumbar lordosis. Regarding the axial plane, the technique of indirect derotation with pedicle screws presented $64 \%$ correction of the apical vertebra, far superior to the old CD system with hooks: $33 \%$ correction. The correction obtained with indirect derotation and pedicular screws was comparable to that obtained with Suk DVR-approximately $74 \% .{ }^{15}$ Rodrigues et al. ${ }^{20}$ used the Nash-Moe method to evaluate the rotational correction of the apical vertebra between the pre- and postoperative periods, and obtained a measurable axial correction in $52.38 \%$. In our study, $32.14 \%$ of the patients presented a measurable correction in the apical vertebra. This divergence can be justified by the greater severity of the cases evaluated. While Rodrigues et al. ${ }^{20}$ found $62.38^{\circ}$ for the thoracic curves and $40.52^{\circ}$ for the lumbar curves on average in the preoperative period, our mean value was $78.3^{\circ}$. The significant difference found in the axial correction of the ends of the scoliotic curve might suggest that isolated derotation of the stems is sufficient for the global derotation of the curve. However, if the surgical goal is to achieve more aggressive derotation at the apex of the curve, the aggregate use of DVR maneuvers in the apex region might be important.

Tang et al. ${ }^{21}$ prospectively assessed patients undergoing DVR versus indirect derotation using a computed tomography (CT) protocol. They also evaluated clinical criteria using the Spinal Appearance Questionnaire (SAQ) and SRS-22 Questionnaire (SRS-22). Although there was more correction with DVR compared to rod derotation, the difference was not statistically significant and did not result in better clinical results or correction of the hump. ${ }^{21}$ Seki et al. ${ }^{22}$ evaluated the correction of axial rotation with the stem derotation and DVR techniques using intraoperative tomography. DVR resulted in a slight but significant additional rotational effect in reducing the axial deformity after the initial indirect derotation, but the greater axial correction did not generate better results in the clinical evaluation. ${ }^{22}$ 
We acknowledge the absence of correlations between the correction obtained and evaluation of quality of life, pain and satisfaction using questionnaires as a limitation of our study.

The Cobb correction was $54.8 \%$, which is comparable to the values obtained by Rodrigues et al. $.^{20}: 61.36 \%$ for thoracic curves and $53.66 \%$ for lumbar curves. However, these values were lower than those obtained by Hempfing et al $^{23}$ and Gotfryd, ${ }^{24}$ which were $71.9 \%$ and $74 \%$, respectively. Comparing the preoperative angular value and the absolute angular value correction, we found mean values of $78.3^{\circ}$ of preoperative Cobb and $42^{\circ}$ of absolute correction, which were higher than those found by Rodrigues et al., ${ }^{20} \mathrm{Hempfing}$ et al. ${ }^{23}$ and Gotfryd. ${ }^{24}$ The greater severity of the cases in our study could justify the lower relative correction.

Regarding the density of implants, we obtained a value of $74.6 \%$, which is superior to that achieved by applying the CD strategic vertebrae concept ${ }^{8,13,24}$ (59.9\%) and comparable to that of Suk's segmental instrumentation concept ${ }^{11,12,14,18,24}$ (80.3\%). Currently, the real value of constructions with high implant density is being questioned. Le Naveaux et al. ${ }^{25}$ demonstrated that low-density instrumentation with strategically placed screws mainly in the concavity of the curve resulted in correction similar to that of high-density instrumentation. Increasing the number of implants led to limited improvement of the three-dimensional correction and excessive stiffness, increasing the forces on them. ${ }^{25}$

On average, more fused levels were identified in our series (11.9) than those identified in the literature (8.4). ${ }^{24}$

Although CT is becoming a popular method to evaluate the axial deformity of scoliosis, the higher radiation load to which the patient is exposed and the greater added cost must be considered. ${ }^{4,26}$ Despite the many advantages of these new technologies, radiographic methods remain the least expensive, safest and most commonly used, serving as baselines for the accuracy of future developments. ${ }^{4,26}$ Radiographs are routinely obtained orthostatically, whereas CT is obtained in the supine position, which causes the deformity to appear less severe in terms of both curvature and rotation.,26 The Nash-Moe method uses two-dimensional radiography to measure three-dimensional changes. However, it can be performed quickly by both experienced and training surgeons for a safe and inexpensive evaluation of the surgical maneuvers performed. ${ }^{4,26}$ Other methods, such as intraoperative tomography, are not available in the majority of spine surgery centers worldwide. Although the Nash-Moe method is less accurate than the Perdriolle method, we chose the former because of its greater applicability and reproducibility.,26

We identified no studies that evaluated the use of the Nash-Moe method for the correction of the curve in the extremities or the apex in patients treated by derotating the rod with segmental instrumentation using pedicular screws. We believe in the effectiveness of this method for spinal axial rotation analysis. Future comparative studies with larger populations may prove the efficacy of this method for the evaluation of pre- and postoperative results on the axial plane.

\section{CONCLUSION}

Rod derotation with screw instrumentation and without the use of DVR, as recommended by Cotrel-Dubousset, can correct all three planes of deformity. On the axial plane, the deformity correction can be satisfactorily evaluated using the Nash-Moe method.

AUTHORS' CONTRIBUTIONS: Each author contributed individually and significantly to the development of this article. FFA (0000-0002-0746-265X)*: writing of the manuscript, statistical analysis, revision of the manuscript, and surgeries; OBL (0000-0002-2614-1771)*: surgeries, data analysis, and writing of the manuscript; RMM (0000-0001-5958-5646)*: image analysis and review of the manuscript; AFC (0000-0002-7797-5274)*: writing and review of the manuscript and intel-lectual conceptualization of the paper; TEPBF (0000-0002-7969-7845)*: surgery, writing of the manuscript, statistical analysis, and intellectual conceptualization of the paper, and preparation of the entire research project. *ORCID (Open Researcher and Contributor ID).

\section{REFERENCES}

1. Adobor RD, Rimeslatten S, Steen H, Brox JI.. School screening and point prevalence of adolescent idiopathic scoliosis in 4000 Norwegian children aged 12 years. Scoliosis. 2011;6:23.

2. Nery LS, Halpern R, Nery PC, Nehme KP, Stein AT. Prevalence of scoliosis among school students in a town in southern Brazil. Sao Paulo Med J. 2010;128(2):69-73.

3. Silva FE, Lehman Jr RA, Lenke LG, et al. Idiopathic scoliosis. In: Herkowiitz HN Garfin SR, Eismont FJ, Bell G, Balderston R, eds. The Spine. $6^{\text {th }}$ ed. Philadelphia, PA: Elsevier Saunders, 2011.

4. Lam GC, Hill DL, Le LH, Raso JV, Lou EH. Vertebral rotation measurement: a summary and comparison of common radiographic and CT methods. Scoliosis. 2008;3:16.

5. Nash Jr CL, Moe JH. A study of vertebral rotation. J Bone Joint Surg Am. 1969;51(2):223-9.

6. Harrington PR. Treatment of scoliosis. Correction and internal fixation by spine instrumentation. J Bone Joint Surg Am. 1962;44-A:591-610.

7. Goldstein LA. Treatment of idiopathic scoliosis by Harrington instrumentation and fusion with fresh autogenous iliac bone grafts. J Bone Joint Surg Am. 1969;51(2):209-22.

8. Cotrel Y, Dubousset J, Guillaumat M. New universal instrumentation in spina surgery. Clin Orthop Relat Res. 1988;227:10-23.

9. Bridwell $\mathrm{KH}$, McAllister JW, Betz RR, et al. Coronal decompensation produced by Cotrel-Dubousset "derotation" maneuver for idiopathic right thoracic scoliosis. Spine (Phila PA 1976). 1991;16(7):769-77.

10. Shufflebarger HL, Clark CE. Fusion Levels and Hook Patterns in Thoracic Scoliosis with Cotrel-Dubousset Instrumentation. Spine (Phila PA 1976). 1990;15(9):916-20.

11. Suk SI, Lee CK, Min HJ,Cho KH, Oh JH. Comparison of Cotrel-Dubousset pedicle screws and hooks in the treatment of idiopathic scoliosis. Int Orthop. 1994;18(6):341-6.

12. Suk SI. Pedicle screw instrumentation for adolescent idiopathic scoliosis: the insertion technique, the fusion levels and direct vertebral rotation. Clin Orthop Surg. 2011;3(2):89-100.

13. Dubousset J, Cotrel Y. Application technique of Cotrel- Dubousset instrumentation for scoliosis deformities. Clin Orthop Relat Res. 1991;(264):103-10.

14. Lee SM, Suk SI, Chung ER. Direct vertebral rotation: a new technique of three-dimensional deformity correction with segmental pedicle screw fixation in adolescent idiopathic scoliosis. Spine (Phila PA 1976). 2004;29(3):343-9.

15. Kadoury S, Cheriet F, Beauséjour M, Stokes IA, Parent S, Labelle H. A three-dimensional retrospective analysis of the evolution of spinal instrumentation for the correction of adolescent idiopathic scoliosis. Eur Spine J. 2009;18(1):23-37.
16. Delorme S, Labelle H, Aubin CE, de Guise JA, Rivard $\mathrm{CH}$, Potras $\mathrm{CH}$, et al. A three-dimensional radiographic comparison of Cotrel-Dubousset and Colorado instrumentations for the correction of idiopathic scoliosis. Spine (Phila Pa 1976). 2000;25(15):205-10.

17. Labelle H, Dansereau J, Bellefleur C, de Guise J, Rivard CH, Poitras B. Peroperative three-dimensional correction of idiopathic scoliosis with the Cotrel-Dubousset procedure. Spine (Phila PA 1976). 1995;20(12):1406-9.

18. Suk SI, Lee CK, Chung SS. Comparison of Zielke ventral derotation system and Cotrel-Dubousset instrumentation in the treatment of idiopathic lumbar and thoracolumbar scoliosis. Spine (Phila PA 1976). 1994;19(4):419-29.

19. Blanke KM, Kuklo TR, O'Brien MF, Lenke LG. Clinical Photographs and Radiographic methodology to Evaluate Spinal Deformity. Radiographic Measurement Manual. In: O’Brien MF, Kuklo TR, Blanke KM, Lenke LG. Radiographic Measurement Manual. Menphis, USA: Medtronic Sofamor Danek USA, 2008. p. 11-30.

20. Rodrigues LM, Yonezaki AM, Ueno FH, et al. Adolescent idiopathic scoliosis: analysis of the degree of correction obtained with pedicle screws. Arquivos Brasileiros de Ciências da Saúde. 2009;35(1):7-11.

21. Tang X, Zhao J, Zhang Y. Radiographic, clinical, and patients' assessment of segmental direct vertebral body derotation versus simple rod derotation in main thoracic adolescent idiopathic scoliosis: a prospective, comparative cohort study. Eur Spine J. 2015;24(2):298-305.

22. Seki S, Kawaguchi Y, Nakano M, Makino H, Mine H, Kimura T. Rod rotation and differential rod contouring followed by direct vertebral rotation for treatment of adolescent idiopathic scoliosis: effect on thoracic and thoracolumbar or lumbar curves assessed with intraoperative computed tomography. Spine J. 2016;16(3):365-71.

23. Hempfing A Ferraris L, Koller $\mathrm{H}$, Rumo J, Metz-Stavenhagen P. Is anterior release effective to increase flexibility in idiopathic thoracic scoliosis? Assessment by traction films. Eur Spine J. 2007;16(4):515-20.

24. Gotfryd AO. Tratamento cirúrgico da escoliose idiopática do adolescente com parafusos pediculares: a densidade de implante influencia nos resultados clínicos e radiográficos? Ensaio clínico randomizado. Faculdade de Ciências Médicas da Santa Casa de São Paulo - Curso de Pós-Graduação em Ciências da Saúde. Tese de Doutorado. São Paulo, 2012

25. Le Navéaux F, Larson AN, Labelle H, Wang X, Aubin CÉ. How does implant distribution affect $3 \mathrm{D}$ correction and bone-screw forces in thoracic adolescent idiopathic scoliosis spinal instrumentation? Clin Biomech (Bristol, Avon). 2016;39:25-31.

26. Cerny P, Marik I, Pallova I. The radiographic method for evaluation of axial vertebral rotation - presentation of the new method. Scoliosis. 2014;9:11. 